\title{
ATATÜRK DÖNEMINDE DEMOKRASI
}

\author{
Prof. Dr. Sina AKŞı̀
}

Önce neden bu konuyu ele aldığımı açıklamak istiyorum. Günümüzde Atatürk'ü seven, ona hayranlık ve baglılık duyan pek çok insan, aynı zamanda o dơnemde "demokrasi" olmamasından ötürü bir rahatsızlık duymaktadırlar. Bu gibilere sorunu açı̋̆ınızda, savunma olarak genellikle söyledikleri, onun bir devrim dönemi olduğu, devrimlerin ancak yetkeci yönctimlerle yapılacağı, dolayısıyla demokratik bir yönetim bcklememek gercktigidir. Bu da bir görüş̧ür. Fakat benim edindigim iżlenim, sorunun, bu tür açıklamalara rağmen, Atatürkçülerde genellikle bir sıkınu kaynağı olduğudur. Bu incelemenin amacı, dönemi demokrasi bakımından incelcyerek, böylesine bir duygunun yerinde olup olmadığını anlamaya çalışmakur.

Incelemeyc başlamadan önce demokrasi kavramından ne anladı̆̆ımı belirtmeliyim. Demokrasi, kimilerinin sandiğı gibi, yalnızca birden çok siyasal partinin bulundugu ve dürüst seçimlerin yapıldığı bir düzen midir ? Hemen belirteyim ki ben böylesine bir tanımı yetersiz buluyorum. Evct, demokrasinin tam, 'dört başı mamur' olması için sözüi geçen koşulların varlığı şartur. Şartır ama, yetèli değildir. Zira bu mekanizmalar tam demokrasi sayamayacał̧ımız toplumlarda da varolabilir. Bir konuşmasında Coşkun Kırca'nın gosterdiği örnckleri vermek gerekirse, eski Atina'da partilere benzeyen gruplar ve özgür scçimler vardı, ama bu, bugünkü görüşümüze göre çok eksik bir demokrasiydi. Günümüz Iran'ında da aynı durumu gözlüyoruz (orada seçimlerin dürüst yapıldığını varsayıyorum). $O$ da cksik bir demokrasidir. Neden ? Zira eski Atina'da kölelik vardı, kadınların ve çok sayıda olan yabancıların siyasal hakları yoktu. Bugün Iran'da da kadınların hakları yoktur, ve daha da önemlisi, düşünce açıklamak ve düzene aykın düşünceleri örgütlcmck özgürlügüü yoktur. Sokrates'e yapılan muamele düşünülürse, eski Atina'nın düşünce özgürlügü alanında da kusurlu olduğu sőylenebilir. Demek ki tam demokrasi olması için Fransız Ihtilalinin getirmiş oldugu eşitlik ve özgürlük esasłannı da anyoruz.

Bir noktayı daha açıklamalıyım. Ülkeleri, toplumları demokrasi bakımından karşılaşurırken anlamlı sonuçlara varabilmek için bir uçta tam demokratik toplum ile obü̈r uçta hiç demokratik olmayan toplum kategorileri arasında bazı ara kategoriler, dereceler de kabul eımemiz gerckir. Tıpkı suyun kaynadıgı $100^{\circ} \mathrm{C}$ ile donduğu $0^{\circ} \mathrm{C}$ arasında (ve ötclerinde) bir çok derecelere ihtiyacımız olduğu gibi... Somut bir omek 
vermek gerckirse: hiç demokratik sayılamayacak iki toplum düşünelim. Ömeğin Iran ve Suudî Arabistan, ya da Mussolini Italyası ile Hitler Almanyası. Diyelim ki bunlardan birinde oturmak zorundasınız ve demokrasiyi yeğleyen bir kişisiniz. Seçiminizi yapmak için yakından incelediginiz zaman göreceksiniz ki, biri büyük ihtimalle diğerinden biraz olsun daha demokratiktir. Başka bir deyişle, inceleme yaparken, az ya da çok sıcak gibi, az ya da çok demokratik kavramlannı da kabul etmemiz gerckiyor.

$$
x \quad x
$$

Bu girişten sonra Atatürk Türkiye'sinin bazı alanlarına bir göz atarak, ne derecede demokratik olduğunu anlamaya çalışalım.

Basın ve yayın hayatına bakalım önce. Kurtuluştan hemen sonra basının az çok ozgür olduğu søylenebilir. Seyh Sait ayaklanması üzerine 1925 'de çıkarılan Takrir-i Sükûn Kanunuyla durum deģişmiş, bir çok gazete ve dergiler kapatılmış, gazeteciler Istiklal Mahkemesinde yargılanmışlardır. Serbest Fırka denemesinin ardından muhalif basın yine baskılara uğramışır. 1931'de çıkan Matbuat Kanunu hilafet ve saltanatçılığı, anarşizm ve komünizmi yasaklıyor ve idareye geçici gazete kapatma cezası verme yetkisini tantyordu. 1933'de lçişleri Bakanlığına bał̆lı bir Matbuat Umum Müdürlügü kuruldu. 1938'de gazete çıkarmak artık bildirimle değil, ruhsatla mümkün hale getirildi. Bu baskı ve kısıtlamalara rağmen basın hayatının hayli canlı olduğu söylenebilir. Gazetelerin yanında bir çok dergiler çıkmıştır: Scrtellerin Resimli Ay'ı (1924), Kadro ve Kooperatif (1932), Ülkü, Fikir Hareketleri, Varlık, Yeni Adam, Yedigün (1933), Yücel, Ayda Bir (1935).

Nazım Hikmet'in durumu ilginçtir. Iki mahkûmiyeti olmakla birlikte, 1938'e değin uzun süre hapis yatmamıştır. 1938'de 28 yıl 4 ay hapse mahkûm olması olayında Atatürk'ün ağır hasta oluşunun ve Fevzi Çakmak'ın ağırlığını koymasının etkili olduğu sőylenir. 1936'ya deģin şiir kitaplanı yayımlanmaya devam etmiş̧ir. II. Dünya Savaşını hapiste geçiren şairin kitapları Savaşın sonunda yasaklandı. Bu yasaktan sonra, Türkiye'de ilk kez bir şiirinin yayımlanması, ölümünden iki yıl sonra, 1965'dedir. Türk edebiyatının en büyük şairlerinden biri olmasına rağmen komünist olduğu ve Rusya'ya kaçıt̆g iç̧in şiirleri hâlâ okul kitaplarına girmiş değildir. Oysa Sèvres antlaşmasına imza koymuş olan Rıza Tevfik'in şiirlerinin okul kitaplarında nicedir yeri vardır. N. Hikmet orneği Atatürk'ten bu yana az çok yetkeci bir düzende yaşadığımızı, fakat Atatürk dőneminde sola açık bir yetkeciliģin, sonraki dőnemlerde de sola kapalı bir yetkeciliğin söz konusu olduğu anlaşılır.

Siyasal düzene bakuğımızda, genel olarak ycukeci tek-parti yơnetimi niteliğinin ağır bastığını kabul etmek gerekir. Çok-partili düzen ancak çok kısa süreler yürürlükte olmuştur. 1924'te kurulan Terakkiperver Cumhuriyet Fırkası ertesi yıl kapatılmıştır. 1930 'da kurulan Serbest Cumhuriyet Fırkası ancak 3 ay açık kalabilmiştir. Böyle olmakla birlikte yetkeciliǧin göründügü denli-koyu olmadığına işaret eden iki olay vardır. Biri, 1924 Anayasasıdır. M.Kemal daha serbest davranabilmek için dogrrudan halk tarafından seçilmeyi, başkanlık dizgesini yeğlcycbilirdi. Bunu yapmamıştır ve Anayasa Komisyonu sözcüsü Celal Nuri, ABD türü kuvvctler ayrılığının Amerikan kıtasına ait bir usûl sayılarak, bilinçli olarak hesap dışı tutulduğunu açıklamıştır. Yine Anayasayla ilgili olarak, TBMM önüne gelen tasarıda cumhurbaşkanlığı süresinin 7 yıl olması, 
cumhurbaşkanının TBMM'yi feshedcbilmesi, başkomutanlık yetkilerine sahip olması öngörüldügü halde, TBMM Genel Kurulu bunları reddetmiştir. ${ }^{1}$

Ikinci olay 1930'larda cercyan etmiştir. 1931'de Recep Peker CHP'nin Genel Sckreteri olmuştu. Ertesi yıl Peker ltalya'ya bir ziyarette bulundu. Oradayken ağırlandı, incelemelerde bulundu. Anlaşılan faşizm onu haylı etkilemiş olacak ki Halk Partisi için faşizmden esinlenen bir program ve tüzük taslağı hazırladı. Söylendiğine göre, taslak bazı kademelerden geçerek M. Kcmal'c ulaştı. M. Kemal, Ismet Paşanın bu "saçmaları" okumadan imza cttiģini söyleyerek, onaylamayı reddetti. ${ }^{2} 1936$ 'da Peker görevinden affedildi ve ondan sonra da Dahiliye Vekilinin kendiliģinden CHF Genel Sekreteri, Valilerin de kendiliklerinden CHF il başkanları olmaları kararlaşırıldı. Gerçi bu, kimilerine yetkeciligin bütüncüllüge (totaliterliğe) varan bir derecesi olarak görünebilirse de, aslında tam tersine, devletin partiyi yutması olarak yorumlanmalıdır. ${ }^{3}$ Yani bütüncül düzenierdckinin tersinc, devlet partileşmiyor, parti devletleşiyor, başka bir deyişle parti bðylece etkisini yitiriyordu. Bütüncül düzenlerde parti hem halkın, hem devletin içinde örgütlenmiş ve egemen durumdadır. Oysa Atatürk döneminde CHP'nin örgütlenmesi, bazı yörelerde düpedüz yok olmak derecesine zayıftu.

Siyasal düzeni gördükten sonra üniversiteye bakalım. 1933 y1lında Istanbul Darülfünunu kaldırıldı, yerine Istanbul Üniversitesi kuruldu. Bu hareketle Darülfünunda çalışan 151 ögretim mensubundan 59'u Istanbul Üniversitesinde çalışmaya devam edebildiler, diģerleri kadro dışı bırakılmışı. Hemen belirteyim ki, ben üniversitelerde bu tür toplu tasfiyelere ilke olarak tamamen karşıyım. Bir bilim adamı ancak aynı kurumda çalışan meslekdaşları tarafından bilimsel yetersizliģi ya da yolsuzlựu yüzünden ve ciddî bir inceleme sonucunda işinden çıarılabilmelidir. Alman bilim adamları Türkiye'ye gelmeselerdi, söz konusu tasfiye üniversiteye çok ağır bir darbe olacaktı. Zaten sanırım Alman bilim adamlanının gelecekleri bilindiģi için bu tasfiye yapılabilmiştir.

Şimdiye değin ele aldığım alanlarda, görüldüğ̈ gibi, Atatürk döneminin sicili genellikle pek olumlu deł̧ildir. Şimdi bu sicilin çok daha olumlu olduğu iki alana geliyoruz. Birincisi, kadın hakları alanındadır. Bu alanda kadın-erkek eşitliği yönünde onemli ve devrimci ilerlemeler sağlandı. Bunu mümkün kılan laiklikti. II. Meşrutiyet de kadının özgürleşmesi için önemli adımlar atmış̧ı, ama laiklik kabul edilmediği için ileri adımları çok kez geri adimlar izleyebiliyordu. Asıl ilerlemeler laiklik ortamında, Cumhuriyetle birlikte olanaklı hale gelmiştir. Zira laiklik Şeriatın toplum üzerindeki ve ozzcllikle kadınlar üzerindcki ortaçaģcıl baskısını kaldırmıştır. Şeriat erkeğe göre kadını yan-insan saymaktaydı. Bunu somut hükümlerinde görebiliyoruz: bir erkeğin tanıklığı iki kadının tanıklığı degererindedir; mirasta erkek tam, kadin yarım hisse alır; evlilikte

\footnotetext{
${ }^{1}$ Mahmut Goloğlu, Devrimler ve Tepkileri (1924-1930) (Ank. Goloğlu Yayınları, 1972), s. 25 v.d. Bugün siyasal sistemimiz, cumhurbaşkanhı̆̆ı görev süresinin milletvekili dönemleriyle aynı olmamasının sıkıntılarını yaşamaktadır. 1919 Weimar Anayasasına göre cumhurbaşkanı halkça doğrudan seçiliyor, ayrıca 1924 Türk anayasa tasarısında óngörülen fakat TBMM'nin kabul etmediği üç nitelik ya da yetkiye sahipti.

2 Mete Tunçay. Türkiye Cumhuriyelïnde Tek-Parti Yönetiminin Kurulması (1923-1931) (Ank., Yurt Y., 1981), s. 321-2 (Soyak I, s. 57-9'dan).

${ }^{3}$ Nitckim Giritlioğlu bunu "Pàrti istiklalinin tamamiyle erimesi" olarak değerlendirmektedir. Fahir Giritlioğlu, Türk Siyasî Tarihinde Cumhuriyet Halk Partisinin Mevkii I (Ank., Ayyıldız Matbaası, 1965), s. 113.
} 
erkek 4 kadınla evlencbilir, "boş ol" sözünü cunckle boşanır, kadının bu hakları yoktur; koca, bazı koşullarda karısını dövebilir. 1926 tarihli Türk Medenî Kanunu, medenî haklarda kadını erkekle hemen hemen tam eşit hale getirmiştir. 1934'te Avrupa'daki pek çok ülkeden once Türk kadınına seçme ve seçilme hakkı verilmekle, siyasal haklarda kadın-erkek eşitliği sağlanmıştır.

Demokratik bir toplumun yapılanması için bunun ne denli önemli olduğu ortadadır. Kadınlar toplumun yarısıdır. Kadınların 'katılmadıgı' bir toplumun yarısı demokrasi dışıdır. Kadını baskı alında tutan bir toplumun istcdigi kadar çok-partili, özgür-seçimli olsun, tam demokrasi olmaktan çok uzak kalacağı bence çok açıkuı. Kadını ezen bir erkek toplumunun içinde de' (yani erkckler-arası) demokrasi olabilecç̧i çok şüphclidir, zira kadınlara tahakküm edenlerin, başka bir deyişle tahakkümü meşrulaşuranların, kendi içlerinde de tahakküm yollan arayacaklan dogaldır sanıyorum.

Atatürk dőneminin demokratik sicilinin olumlu olduğu ikinci bir alan, çocukların dayak korkusundan kurtarılmasıdır, daha dogrusu kurtarılması yolunda ónemli adımların atılmasıdır. Ihtiyatlı bir anlatıma başvuruyorum, çünkü kurumsal ve-yasal olanakların sağlanması ile uygulamada bunlann gerçekleştirilmesi, kullanılabilmesi, çok kez-uzun mücadeleleri, ve az çok uzun sürelerin geçmesine bağlıdır (kadın haklarında da bu bઠbyledir). Yine bu alandaki gelişmelerde de Şcriatın devre dışı burakılması, yani laikliǧin, yaşamsal bir payı olmuştur, zira Şeriat bakımından dayak, doğal ve ónemli bir ceza ve disiplin aracıdır. Uzun zamanlar falaka hapishanelerin, karakolların ve okulların adeta demirbaş aleti olmuştur, okullarda neredeyse bir eğitim aracıydı denebilir. Dayakla ilgili atasőzlerimiz de dayağın ne denli meşru ve olağan görüldü̈günün başka bir kanıtıdır. Cumhuriyetle birlikte mahalle mekteplerine son verilmesi, hocalar yerine ögretmenlerin gelmesi dayağın okullardan kalkması yolunda pek büyük bir adımdır. ${ }^{4}$

Dayağın kalkmasının eğitimbilim bakımından olduğu kadar, demokratik bir toplum inşa etmek bakımından da önemi üzerinde durmak istemiyorum. Yalnız, pek çok aile içinde dayağ in sürmesi dolayısıyla, okullardaki dayak yasağının olumlu etkilerinin yeterince hissedilmedił̧ine, hattâ zaman zaman okullarda dahi dayağın hortlatıldığına burada işaret edilmelidir.

Sonuç bir özet olacaktır. Basında, siyasette, üniversitede Atatürk dőneminin sicili, bugünkü ölçülerimize göre, parlak olmaktan uzaktır. Ama kapkara da deģildir. Her şeye rağmen, dinsel sağa kapalı olmakla birlikte, canlı bir basın hayatı, bir tartışma ortamı vardı. Siyasette, tek parti düzeni olmakla birlikte, iki çok-partili dizge denemesi, bir olçüde kâğıt üzerinde kalmış olsa da liberal bir anayasa, bütüncüllü̈ge genellikle pek olumilu bakmayan bir siyasal tavır vardır. Öte yandan, kadın ve çocuk hakları bakımından parlak diyebileceğimiz temel adımlar atılmış, bugünkü demokrasimizin alt-yapısı oluşturulmuştur.

\section{$x \times x$}

Atatürk dönemini demokrasi ölçütüne göre değerlendirirken dogal olarak bugünkü siyasal düzenimizle karşılaştırıyor ve cksik buluyoruz. Fakat bu karşılaşurma Atatürk'ün çăgdaşı olan başka ülkelerle de yapılmalıdır. O günlerin Avrupasına gơz alı̆gımızda genel, ortalama demokrasi düzcyinin hayli düşük oldugu göze çarpıyor. En bilinen ömcklerden başlarsak, SSCB'de 1917'den başlayarak prolctarya diklatörlügünü görüyoruz.

\footnotetext{
${ }^{4}$ Yahya Akyüz, Türk Egitim Tarihi (Ankara, AUEBF Y., 1989).
} 
Lenin'in ölümünden (1924) sonra SSCB'dcki düzen, Stalin'in yönctiminde gitgide daha baskıcı, bütüncül bir nitcliğc bürünecektir. Italya'da 1922'de Mussolini'nin faşist düzeni kurulacaktır. Almanya'da 1933'te Hitler, 1936 'da Ispanya'da Franco diktatörlüğ̈̈̈ başlamaktadır. Doğu Avrupa'da durum aşağı yukarı aynıdır. Polonya'da 1926 'da askerî bir darbcyle iktidara gelen Mareşal Pilsudski diktatör olmuştur. Macaristan bu dönemde hep Italya ve sonra da Nazi Almanya'sına yakın olmuş, ülkeyi gittikçe diktatörleşen Amiral Horthy yönetmiştir. Romanya'da Kral II. Karol ayn biçimde diktatörleşti. Yugoslavya'da Kral Alcksandr'ın diktatörlü̈ünü görüyoruz. Arnavutluk'ta cumhurbaskanı olan Ahmet Zogu 1928 'de krallığını ilân etli ve bu yüzden Türkiye ile ilişkileri bir süre bozuldu. Bulgaristan'da 1923, 1934, 1935'de askerî darbeler oldu. 1936'dan başlayarak Çar Boris diktatör durumuna geldi. Yunanistan'da yıllarca krallık mı, cumhuriyet mi olsun mücadelesinden sonra II. Yorgi yeniden kral oldu. 1936'da yaptığı darbe sonucunda General Mctaksas diktatör oldu. Avusturya 1933'de diktatörlük oldu, sonra da Almanya'ya ilhak edildi. Portckiz'de 1928'den itibaren Salazar diktatör oldu. Genel olarak Lituanya, Latvia ve Estonya, ozcllikle 30'lu yıllarda gittikçe diktatörlüğe kaymışlardır.

Bu dönemde Avrupa'da az çok demokratik sayılabilecck ülkeler Ingiltere, Fransa, Benclüks, Isviçre, Iskandinavya, Finlandiya, Çekoslovakya'dır. Bunlardan Fransa'nın durumu ilginçtir. Almanya'ya savaş ilan ettikten az sonra, Fransız Meclisi 26 Eylül 1939'da Komünist Partisini dağıtma ve yayınların yasaklama karan aldı. Ocak 1940'da daha ilcri gidilerek Komünist milletvekillerinin Meclis üyelikleri iptal edildi. Gerekçe Sovyet-Alman Pakıydı ama Komünistler savaş odenekleri Konusunda öbür partilerle birlikte oy vermiş bulunuyorlardı. Bütün bunlar olurken Almancı çevrelere karşı hiç bir 'önlem' alınmadı. Görülüyor ki Fransa'da bir oydaşma kırılması oluyor ve ülke sanki savaş halinde oldư̆u düşmanına yanaşıyordu. Yenilgi gelince, Fransa düzenini deģiştirdi, ve bu demokrasi 'beşigii' açık seçik bir faşizme yöneldi. Bu faşizmin yenilgi ve Alman işgaliyle ne ölçüde doğrudan ilintili olduğu tartı̧ılabilir, zira Vichy hükümeti işgal alunda olmayan bir bölgede bulunuyordu. Artuk Fransa bir cumhuriyet değildi, Mareşal Petain de cumhurbaşkanı olmak yerine yalnızca devlet başkanıydı. 1789'da kabul edilmiş olan Insan ve Yurttaş Hakları Bildirgesi yürürlükten kaldırıldı. Devletin temel ilkeleri de dç̧işti: "ozgürlük, eşitlik, kardcşlik" yerine "çalışma, aile, vatan" geldi. ${ }^{5}$

Görülüyor ki diktatörlük, bu dönem Avirupasında olağan bir durumdu. Atatürk'ün tck-parti yönetimi de diktatörlük değil miydi ? Şüphesiz buna diktatörlük denebilir. Ama Atatürk düzeninin öbür diktatörlüklerin çogundan, belki hepsinden, daha ehven bir nitcliği vardı. Bir kez bütüncül deł̧ildi. Ikincisi, obbür diktatőrlüklerin bir çoğunda ırkçılık, azgın bir Yahudi düşmanlı̆̆ı, azgın bir sol düşmanlığı (SSCB'de sặ düşmanlığı) vardı. Türkiye'de ise düzenin kesin olarak düşman olduğu tek şey ontaçağcıl gericilik ve yobazlıkı, ki bunları da demokratik hareket ve tavırlar olarak nitelemek zordur.

\section{$\mathbf{x} \mathbf{x}$}

Öylc anlaşılıyor ki, Avrupa, iki Dünya Savaşı arasında bugünkü denli kapsamlı bir demokrasiyc geçmek konusunda ne hazır, ne de istekliydi. I. Dünya Savaşı sonunda Rusya, Almanya, Avusturya, Macaristan, Türkiye, Yunanistan, Polonya, Portekiz gibi ülkelerde cumhuriyeulerin kurulması bir demokratikleşme adımı olmakla birlikıe, sonuç çok kez. diktatörlük oluyordu. Ünlü bir toplumbilimci, Max Weber (1864-1920), daha dönemin başında diktatörlüklerin, bu arada bütüncül diktatörlüklerin, kuramını yapıyordu.

${ }^{5}$ Robert Aron, Histoire de Vichy, I (Paris, Fayard, 1966), s. 306 
Karizmatik önder kavramı yetkeci bir cumhuriyet türünü bize işaret ediyor. Versailles Barı̧ Antlaşması yapilırken (1919) Alman murahhas heyetinde bulunan Weber'le General Ludendorff arasında geçen şu görüş̧me bunu çok iyi anlauyor :

"Weber: Bugünkü hayvanca durumumuzun demokrasi oldug̛unu düşündügümü mü saniyorsunuz?

Ludendorff: Boyle diyorsanız, belki anlaşınz.

W. : Fakat onccki hayvanca durumumuz da salıanat deģildi.

L. : O halde demokrasiden ne anlıyorsunuz ?

W. : Demokraside halk güvendiģi bir onder seçer. Seçilen onder 'Şimdi sesinizi kesin ve bana itaat edin.' der. Artık halk ve parti onun işine kanş̧amazlar.

L. : Boyle bir demokrasiye ben vanm.

W. : Sonra halk oturup onu yargılar. Onder hatalar yapuysa, doğnu darağacına!"6

Görülüyor ki, Weber ve çağdaşları, saltanatı arık kabul etmemekte, ama çoğulcu bir demokrasiye de hazır deģillerdir. Geriye karizmatik önder, daha açıkçası, çok kez diktatơr durumundaki onder almaşığı kalıyordu. Bu hükümetler cumhuriyetti ama onderleri çok kez krallara, padişahlara benziyorlardı. Zaten 20'lerin başlarındaki cumhuriyetçilik akımı sonradan tavsamış, yer yer saltanata dönüşler olmuştur. Weber'in dehası, daha đönemin başında, henüz Mussolini bile ortaya çıkmadan, karizmatik önder tipini, yani Duçe'leri, Führer'leri, Lenin-Stalin'leri kavramlaştırıp tanımlamıs bulunuyordu. Atatürk ve De Gaulle bu tipin yumuşak, ılımlı, çoğulculuğa açık ornekleridir. (De Gaulle daha sonraki bir dönemde iktidara gelmiş olmak itibariyle, çağdışı kalamayacağı ve zaten ilke olarak da Vichy düzeniyle kavgahı olduğu için zorunlu olarak Atatürk'ten daha demokratik olmuştur).

Yazının başında ortaya koymaya çalışı̆̆ım gibi, her ülkenin bir demokrasi derecesi varsa, bu surada Avrupa'nın ortalama demokrasi derecesi haylı düşüktü. Ayrıca, bana oyle geliyor ki, Atatürk Türkiye'sinin demokrasi derecesi bu ortalamanın üstündeydi. Bunu tartışma konusu yapmak isteyenler olabilir. Ben de bu konuda fazla ısrar etmek istemem. Ama bence şu kesindir: Atatürk döneminin demokrasi derecesi demokratik olmayan Avrupa ülkelerinin demokrasi ortalamasının mutlaka üstündeydi. Demokrasi derecesi diyorum ama ne yazık ki demokrasi ölçen bir aletimiz yok ki ölçüm yapabilelim. Bununla birlikte savımı tanıtlayacak bazı kanıllar ileri sürebilecȩ̧imi sanıyorum.

Avrupa'da diktatörlük kâbusu karabulut gibi ortalığı kaplamışı ama yine de Ingiltere ve 1940'a değ in Fransa gibi ağırlıklı ülkeler demokrasi düzeninde yaşıyorlardı. Daha onemlisi, Allas Okayanusunun öbür yakasında ABD gibi dev bir gụ̧̈ demokrasi kalesi durumundaydı. Ve diktatörlüklerin kendilerine hayran yaygaracılıklarına rağmen, dünya kamuoyunda demokrasi daha itibarlı bir düzendi. Türkiye'nin de ondan önce uzun zaman, ondan sonra da bugüne dek sahip olmadı $\grave{\jmath}_{ı}$ bir itibarı vardı o dönemde. Bence bu itibar, büyük ölçüde Türkiye'nin demokrasi derecesinin görece yüksckliğinden kaynaklanıyordu. Şimdi bunun göstergelerini görelim.

1. Atatürk resmî ya da özel hiç bir dış geziye çıkmadı̆̆ı halde Avrupa'nın bir çok devlet adamı Türkiye'ye gelmiştir. Romen, Yugoslav Kralları, Venizelos, Macar

${ }^{6}$ H.H. Gerth, C. Wright Mills, From Max Webcr: Essays in Sociology (N.Y., Galaxy, 1958), s. 42 (Marianne Weber. Max Weber: ein Lebensbild'den). 
Başbakanı, cski Fransız Başbakanı Herriot, Isveç Vcliahdı, Dr. Schacht, Litvinof, Voroşilof, ve en onemlisi, Ingiliz Kralı VIII. Edward (1936'da) Türkiye'yi ziyaret etmişlerdir.

2. 1920'ye gelindiłginde, eski dünyada Avrupalı olmayan ve bağımsız kalabilmiş 4 ülke bulunuyordu : Çin, Habeşistan, Iran, Türkiye. Çin 1931'de Japon, Habeşistan 1935'te Italyan, Iran 1941'de Sovyet-Ingiliz istilasına uğradılar. Türkiye kendini bu yazgıdan kurtarabildi. 1934'tc Mussólini'nin emperyalist bir demeci Türkiye'de tedirginliğe yol açmışı. Bunun üzcrine hem Italyan Dışişleri Bakanlığı Müsteşan, hem de bizzat Mussolini, Türk Büyükelçisine, Türkiye'nin söz konusu demecin kapsamı dışında olduğunu, zira bu ülkenin bir Avrupa ülkesi olduğunu belirımişlerdi.7 Türkiye'nin bu Avrupalı sayılmasında, ve bu sayede Çin, Iran, Habeşistan'ın yolunda gitmemiş olmasında görece yüksck demokrasi derecesinin de bir payı olmalıdır diye düşünüyorum.

3. 1933'ten itibaren 142 Alman ve Avusturyalı bilim adamı (78'i profesör ya da doçent) Türkiye'ye gelmiş ve çoğu 1945'e kadar Türkiye'de kalmışlardır. Bunlar Hitler Almanya'sının üniversitelerinden düzene muhalif diye kovduğu demokrat, solcu, Yahudi bilim adamlarıydı. Işlerinden aulmış, ülkelerinde bannma olanağı bulamayan bu insanlar, ne kadar süreceği belirsiz uzunca bir zaman hizmet vermek için gelmişler ve genellikle kendileri için pek ilginç sayılamayacak bir dil olan Türkçeyi kısa sürede ơgrenip bu dilde ders vermeyi kabul etmişlerdir. Burada gç̧ici bir iş almak deģil, adeta bir yerleşme sơz konusudur. $O$ derecede horlanmış olán bu kişiler bu derecede önemli bir karar almışlarsa, bunu kolayca almadıkları tahmin edilebilir. Herhalde onlar için Türkiye en azından 'yaşanabilir' bir ülke olmalıydı. Geçirdikleri kötü dencyin tekrarlanabileceği bir yere herhalde gelmek istemezlerdi. Ortanın üstünde değeri olan bu bilim adamlarının çaresizlikten Türkiye'ye geldikleri de söylenemez. Bir çoğu dünya çapında uzmanlardı, bir çoğu da 1945'ten sonra ABD'de kenđilerine parlak işler bulmuşlardır. Herhalde onlar, Türkiye'nin demokrasi derecesini Avrupa diktatörlüklerinin ortalamasının, muhtemelen Avrupa ortalamasının da çok üstünde görmekteydiler.

4. Dördüncü bir göstcrge Montreux (Montrö) Antlaşmasıdır. Lausanne (Lozan) Antlaşmasıyle Boğazlar askersizleştirilmişti. Başka bir deyişle Türkiye buraları savunmak olanağından yoksun bırakılmıştı. Türkiye Lausanne'ın bu hükümlerinin değiştirilmesini istcdiģi zaman o sıra Avrupa'da büyük bir kutuplaşma ve savaşa doğru koşar adım bir gidiş olduğu halde, önemli bir itiraz olmamış ve Montreux'de $1936^{\prime} \mathrm{da}$ toplanan konferans Türkiye'nin istcklerine uymuşı ki, dedił̣̌im gibi, Türkiye bunu önemli ölçüde demokrasisinin görece yüksek derecesine borçluydu.

Sonuç : Atatürk Türkiye'sinin durumunu gördük. Bugün demokrasimiz Atatürk döncminin alı̆̆̆ı, Inönü döneminin pckiştirdiği sağlam temeller sayesinde demokrasi bakımından Atatürk döneminden çok daha ilerdedir. Çok-partili bir siyasal hayatımız, dürüst seçimlerimiz var. Ayrıca 1961 Anayasasının getirdiği bir çok demokratik kurum ve yöntemler var. Ama ne var ki, 1945'ten beri Avrupa'nın genel demokrasi ortalamasının gerisindeyiz. llk kez Ekim 1991 seçimleri sonucunda kurulan karma

${ }^{7}$ Aptúlahat Akş̧in, Atatiurk'ïn Dıs Politika llkeleri ve Diplomasisi (Ank., TTK, 1991), s. 222. 3. 
hükümetledir ki ülkemizde Avrupa ölçütlerine uygun bir dẹmokrasi kurma konusunda kesin bir umut belirmiştir. Demck ki Atatürk dönemine göre bugün daha demokratız, ama Atatürk donemi Avrupa ortalamasından daha ileriyken, 1945'ten beri o ortalamanın gerisindeyiz. Mutlak olarak ilcrledik ama Avrupa'ya göre geriledik. Bugün MÇP ónderi Türkeş dahi ülkemizde işkence uygulamasından şikâyeıçidir. Onun için kendimizi 'tanıtamıyoruz', onun için dış dünyada görüntümüz bozuktur. ${ }^{8}$

Son olarak diyebilirim ki, günümüz Atatürkçülerinin Atatürk döneminin demokrasi derecesi konusunda utanıp sıkılacakları bir şcy olduğu söylenemez. Her donem, dőneminin ulusal ve uluslararası koşullarına göre değerlendirilmelidir.

8-"Turkiye bir Avrupa ülkesi.olmak zorundadır. Kendimize herhangi bir Asya veya Afrika ulkesi gibi davranabilme 'lüksünü" tanıyamayız. Her alanda evrensel, yani Bat ölçütlerini benimsemek zorundayiz. Yoksa 'Avrupa'nın hasta adami" muamelesi yeniden başlayabilir..." S. Akşin, "Türkiyc'nin Görüntüsü Bozuk mu? ". Cumhuriycl, 4/5/1991. 